\title{
What do health authorities think of population based health outcome indicators?
}

\author{
Alastair McColl, Paul Roderick, John Gabbay, Gill Ferris
}

\begin{abstract}
Objectives-To determine the role of population based indicators of health outcome in local health outcome assessments; the constraints of using such indicators; how they could be made more useful; and whether health authorities had developed their own indicators of health outcome.
\end{abstract}

Design-A structured telephone interview with representatives of 91 of the 100 English health authorities.

Results-Interviewees, asked to give details on two clinical areas in which population health outcome assessments had been of most value, nominated 147 examples in over 30 clinical areas. They chose $50(34 \%)$ of the examples because of an outlying national indicator, and 20 (14\%) because of local variations in a national indicator. The main perceived constraints in the use of population based indicators of health outcome were: data validity and timeliness; the attributability of these health outcomes to the quality of health care; the difficulties of changing clinical behaviour; and organisational change within health authorities. To make these indicators more useful interviewees wanted an increased use of process indicators as proxies for health outcome, indicator trend data, and indicator comparisons of districts with similar population structures. Some recent publications have started to consider some of these issues. 27 (30\%) health authorities had developed their own indicators, mostly provider based process indicators. 10 of these used their own indicators to manage the performance of local provider units.

Conclusions-Population based indicators of health outcome had an important role in prompting districts to undertake population health outcome assessments. Health authorities also used these indicators to examine local variations in health outcome. They helped to highlight areas for further investigation, initiated data validation, and enabled the monitoring of changes to services. Comparative population based indicators of health outcome may have an increasing part to play in assessing the performance of health authorities.

(Quality in Health Care 1998;7:90-97)

Keywords: health outcome; indicators; population; assessments

\section{Introduction}

POTENTIAL VALUE OF POPULATION BASED

INDICATORS OF HEALTH OUTCOME

High quality health care should result in improved health outcome at levels of both the individual patient and the population. Purchasers are concerned about quality at a population level and organisational performance of providers. ${ }^{1}$ They could use comparative national indicators of population based health outcome to help assess health outcome. An outlying value of an indicator in a district, compared with the national mean, could stimulate local discussion or formal assessment.

However, population based indicators of health outcome often reflect the underlying level of disease risk in the population. Purchasers can reduce this risk by detecting and managing risk factors in a coordinated way across all levels of health care. For example, there are significant variations in deaths from peptic ulcer between districts ${ }^{2}$ but not between hospitals. ${ }^{3}$ This suggests that cost effective methods for risk reduction, early diagnosis, and appropriate drug treatment in primary care may be more useful than improvements in hospital care. For many diseases this increases the purchasers' incentives to design and manage an integrated system of health care with prevention programmes that involve alliances with organisations outside the health sector.

Population based indicators of health outcome can also reflect what happens to minimise the consequences of disease once patients are admitted to hospital-for example, by preventing potentially avoidable complications and premature death. For instance, in one English region mortality 90 days after admission for hip fracture differed significantly between hospitals. ${ }^{4}$ Case mix was unlikely to explain these differences as patients admitted to each hospital were similar in age, sex, pre-existing illnesses, and activities of daily living before fracture. Purchasers can use these variations in population based health outcomes within districts to assess the possibility of inappropriate health service delivery or poor access. For example, an investigation into the considerable variations in mortality from coronary heart disease within a district showed that uptake of coronary artery surgery did not correspond with need. ${ }^{5}$

In this paper we use the following definition of population health outcome: the attributable effect of a healthcare intervention on a previous health status at a population level (national, regional, district, locality, or electoral ward). ${ }^{2}$ However, few published studies ${ }^{6-8}$ have examined the attributable effect of healthcare inter- 
There are several varieties of purchasing models in England which are likely to change.

This year there are 101 health authorities purchasing hospital and community health services from NHS trusts. (One health authority has been divided into two since our interview). They do this on behalf of all nonfundholding general practitioners (GPs) (about 10000 GPs are non-fundholders ${ }^{11}$ ) and some services on behalf of GP fundholders and commissioning GPs (see below).

GP fundholders purchase some hospital and community health services directly. Many have chosen to act together in consortia, multifunds, or total purchasing projects to purchase a wider range of services (about $15000 \mathrm{GPs}$ are fundholders ${ }^{11}$ ).

Purchasing involves other GPs. Commissioning groups led by GPs and others led by health authorities are increasing in numbers. GPs also work in various pilot schemes including practice based contracts with total budgets (about 9000 GPs are commissioning $\mathrm{GPs}^{11}$ ).

Directors of public health are employed by health authorities and lead the public health function in their district. ${ }^{12}$ They are executive members of health authority boards. Their responsibilities include assessing local health needs; developing, and as appropriate implementing, local health and health promotion strategies; leading the health authority's work in improving the appropriateness and effectiveness of clinical and non-clinical interventions; and a key role in developing and sustaining relationships between the health authority and clinicians (including GPs), local authorities, and the local community. They are accountable to their health authority for the surveillance, monitoring, and control of communicable disease and non-communicable environmental exposure. They provide the focus for all local public health advice. ${ }^{12}$

Box 1 NHS purchasers in England

ventions on health and the extent to which population based indicators of health outcome directly reflect the quality of health care. Yet purchasers have potentially their most direct influence on health care through contracting.

RELEVANCE OF POPULATION BASED INDICATORS OF HEALTH OUTCOME

Guidance to National Health Service (NHS) purchasers has highlighted the need for assessment of health outcomes. ${ }^{9}{ }^{10}$ In England NHS purchasers consist of health authorities, locality commissioning groups, and general practice fundholders (box 1).

The United Kingdom Health of the Nation target areas ${ }^{10}$ are national comparative population based indicators of health outcome (box 2). Population health outcome indicators for the NHS is another set of such indicators for the health authorities which was first released as a consultation document ${ }^{2}$ and feasibility study ${ }^{13}$ in 1993 (box 2). These indicators build on the avoidable mortality indicators first developed as quality of care indicators by Rutstein $e t a l^{14}$ in the United States and then by Charlton et $a l^{15}$ in the United Kingdom. All the indicators were based on routine data and reflected the effect of health service interventions. They are now in the public health common data set, ${ }^{16} \mathrm{a}$ set of regional and district indicators published annually. In 1993 the Scottish Clinical Outcomes Working Group also presented population and provider based outcome indicators for a limited number of conditions highlighting variations between health boards. ${ }^{17}$

There are other developments relevant to indicators of health outcome in England. Rationalisation and the development of further indicators are currently being undertaken under the auspices of the NHS Executive's Efficiency and Effectiveness Working Group. The Department of Health's Central Health Outcomes Unit has embarked on a programme to identify and develop sets of outcome indicators for several clinical areas. ${ }^{18}$ These include population based and provider based indicators of health outcome. Its design required information about the ways in which such indicators will be used in practice. The NHS Executive and Department of Health have recognised that they need to consider how measures of health outcome can become central to assessing the performance of health authorities and NHS trusts. ${ }^{19} \mathrm{~A}$ recent survey found that improving clinical effectiveness was not a priority for many health authorities and most NHS trusts in England and Wales. ${ }^{20}$ One conclusion was that their performance needs to be measured with indicators that reflect the effectiveness of the services they purchase and provide. Health outcomes are now explicitly being considered by the United Kingdom government. $^{21}$

The further development of indicators required information on how they are perceived and used by their intended audience. A 1993 study examined assessments of health outcome by district health authority purchasers in England but presented limited information on mortality and morbidity indicators in purchasing health care. ${ }^{22}$ Health outcome assessment was in its infancy at that time. Otherwise there have been no relevant surveys. Yet comparative population based indicators of health outcome may have an increasing part to play in assessing the performance of health authorities, and should therefore also be of interest to those who work in health care and who are involved in the management of performance.

This paper presents the results of a survey of English health authorities. The objectives were to determine: the role of population based indicators of health outcome in assessments of local health outcome; the constraints of using such indicators; how they could be made more useful; and whether health authorities had developed their own indicators of health outcome. 
United Kingdom Health of the Nation main target indicators (first published in 1992) ${ }^{10}$

CORONARY HEART DISEASE (CHD) AND STROKE

1 To reduce death rates for both CHD and stroke in people $<65$ by $\geqslant 40 \%$ by the year 2000 (baseline 1990).

2 To reduce the death rate for CHD in people aged $65-74$ by $\geqslant 30 \%$ by the year 2000 (baseline 1990).

3 To reduce the death rate for stroke in people aged $65-74$ by $\geqslant 40 \%$ by the year 2000 (baseline 1990).

CANCERS

4 To reduce the death rate for breast cancer in the population invited for screening by $\geqslant 25 \%$ by the year 2000 (baseline 1990).

5 To reduce the incidence of invasive cervical cancer by $\geqslant 20 \%$ by the year 2000 (baseline 1986).

6 To reduce the death rate for lung cancer in people $<75$ by $\geqslant 30 \%$ in men and by $\geqslant 15 \%$ in women by 2010 (baseline 1990).

7 To halt the year on year increase in the incidence of skin cancer by 2005 .

MENTAL ILLNESS

8 To improve significantly the health and social functioning of mentally ill people.

9 To reduce the overall suicide rate by $\geqslant 15 \%$ by the year 2000 (baseline 1990).

10 To reduce the suicide rate of severely mentally ill people by $\geqslant 33 \%$ by the year 2000 baseline 1990).

HIV/AIDS AND SEXUAL HEALTH

11 To reduce the incidence of gonorrhoea by $\geqslant 20 \%$ by 1995 (baseline 1990), as an indicator of HIV/AIDS trends.

12 To reduce by $\geqslant 50 \%$ the rate of conceptions among girls $<16$ by the year 2000 (baseline 1989).

ACCIDENTS

13 To reduce the death rate for accidents among children aged $<15$ by $\geqslant 33 \%$ by 2005 (baseline 1990).

14 To reduce the death rate for accidents among young people aged $15-24$ by $\geqslant 20 \%$ by 2005 (baseline 1990).

15 To reduce the death rate for accidents among people aged $\geqslant 65$ by $33 \%$ by 2005 (baseline 1990).

Population health outcome indicators for the NHS (developed in 1991 and first published in 1993) ${ }^{2}$

1 District and regional SMRs for deaths for ages 50-69 caused by breast cancer.

2 Regional SMRs for deaths in people $<45$ years caused by diabetes.

3 Regional age standardised admission rates for ketoacidosis and coma / 1000000 residents per year.

4 Regional age standardised operation rates for lower limb amputations in diabetic patients per 1000000 regional residents per year.

5 District and regional SMRs for deaths in people aged 25-74 caused by peptic ulcer. 6 Annual age standardised admission rates for hip fracture per 10000 district and regional residents $>65$ years.

7 District and regional SMRs for deaths in people aged 65-84 caused by fracture of proximal femur.

8 District and regional SMRs for deaths in people aged $\geqslant 85$ caused by fracture of proximal femur.

9 The total legal abortion rate for all districts and regions. 10 The total legal abortion rate as a percentage of the crude potential fertility rate for all districts and regions.

11 The proportion of terminations of pregnancy that are performed after 12 weeks gestation for all districts and regions.

12 District and regional conception rates for those aged $<16 / 1000$ district and regional women residents aged 13-15.

13 Regional rates of infants born with Down's syndrome/100 000 total regional births.

14 Regional proportion of pregnancies with Down's syndrome diagnosed prenatally.

15 Regional rates of infants born with spina bifida / 100000 total regional births.

16 Regional rates of infants born with anencephaly / 100000 total regional births.

17 District and regional SMRs for all deaths due to skull fracture and intracranial injury.

18 Regional SMRs for deaths in children aged $<15$ years due to skull fracture and intracranial injury.

19 Regional SMRs for deaths between the ages of 15 and 24 years due to skull fracture and intracranial injury.

20 The district and regional age standardised rate of notifications of pertussis in children aged $<15$ years.

21 The district and regional age standardised rate of notifications of measles in children under the age of 15 years.

22 The district and regional proportion of children reaching their 1 st birthday who are immunised against pertussis.

23 The district and regional proportion of children reaching their 2 nd birthday who are immunised against measles.

24 District and regional male birth cohort specific orchidopexy rate by the 5 th birthday. 25 Annual district and regional orchidopexy rate in boys aged 5 to 14 years.

26 Annual district and regional proportion of boys undergoing orchidopexy who are over the age of 5 years.

27 Regional age standardised rate of renal replacement therapy/1000000 residents/ year.

28 District and regional SMRs for all deaths with the underlying cause as suicide and self inflicted injury combined with deaths from injuries undetermined, whether accidental or purposely inflicted.

29 District and regional SMRs for deaths in people aged $15-44$ years with the underlying cause as suicide and self inflicted injury combined with deaths from injuries undetermined, whether accidental or purposely inflicted.

30 Regional SMRs for deaths mentioned as associated with schizophrenic psychoses in people aged $<75$ years.

* Many of these indicators are population based process indicators used as proxies for improved health outcome.

Box 2 Some of the national comparative health outcome indicators based on populations published annually in England* 


\section{Methods}

After a series of face to face interviews we developed and piloted the questionnaire. Pilot interviews told us that local directors of public health received four to five postal questionnaires each week from a variety of research groups. We therefore used a telephone interview to ensure a higher response rate than we would have obtained from a postal questionnaire. A steering group advised on and approved the development of the questionnaire. We sent the questionnaire to directors of public health in all 100 English health authorities (box 1) and asked to arrange a semistructured telephone interview with them or a nominated colleague. We sent a further copy of the questionnaire before the interview.

The interview covered the following grounds:

- ROLE OF POPUlation BASED INDICATORS OF HEALTH OUTCOME IN ASSESSMENTS OF LOCAL HEALTH OUTCOME

We asked for two local examples of clinical areas in which population health outcome assessments had been of most value. For each of these areas we asked why they had chosen the area, further information that had been required, whether they had examined data validity, the changes to services that they had made, and what were the resource implications for future services.

- CONSTRAINTS IN THE USE OF POPULATION BASED INDICATORS OF HEALTH OUTCOME We asked them to list the main constraints in the use of such indicators.

- HOW POPULATION BASED INDICATORS OF HEALTH OUTCOME COULD BE MADE MORE USEFUL

We asked how population based indicators of health outcome could be made more useful.

- HEALTh AUTHORITIES DEVELOPING THEIR OWN INDICATORS

We found when we were piloting our questionnaire that health authorities had developed their own indicators of health outcome. Many of these indicators could be used at a provider or population level especially in those health authorities where there was only one local provider. Although the main focus of this study was on population based indicators we thought that it was important to record the local use of all indicators of health outcome as this could have implications for the further development of national population based indicators of health outcome. If health authorities had developed their own indicators we asked whether they were using them to manage the performance of local providers.

SUBJECTS

We interviewed representatives of 91 of the 100 health authorities between October and December 1995. Of those interviewed $68 \%(61)$ were directors of public health, $26 \%$ (21) were consultants in public health medicine, and two were non-clinical epidemiologists, two were research managers, and one was a resource centre manager. We conducted this study at a time of major change in the NHS and only half of those interviewed had been in post for more than two years.

ANALYSIS OF DATA

All the interviews were conducted by AMc with GF listening in to each interview and writing the responses. Immediately after each interview we agreed on the appropriate coding for each response before the data were entered into the database. The interviews were not recorded on tape. We ensured the reliability of the analyses to identify similar phrases, pattern themes, and differences in health authority responses by both $\mathrm{AMc}$ and GF independently analysing the data and drawing their own conclusions for each section of the questionnaire. The coding sheets, data base, and anonymised transcripts from each interview are available.

\section{Results}

ROLE OF POPULATION BASED INDICATORS OF HEALTH OUTCOME IN ASSESSMENTS OF LOCAL HEALTH OUTCOME

Box 3 summarises the key results from this study. We published the full results of the questionnaire in October $1996 .^{23}$ We obtained details on 147 examples in over 30 clinical areas (table 1). Of these examples $60 \%$ were in Health of the Nation areas. Table 2 lists the most common reasons for choosing the examples. Health authorities investigated 50 of the 147 examples $(34 \%)$ because indicators with national data suggested an outlying value. Of these, 32 were Health of the Nation indicators (box 2), nine were from Population indicators of health outcome for the NHS (box 2). Seven were indicators from the public health common data set, and two were derived from general practitioner prescribing data (prescription analysis and cost-PACT data). The health authorities investigated 20 of the examples $(14 \%)$ because they had found variations in population based indicators of health outcome in subdistricts (localities or electoral wards) for rates of termination of pregnancy (seven), mortality from coronary heart disease (five), breast cancer (four), fractured neck of femur (one), orchidopexy (one), perinatal mortality (one), and lung cancer (one).

They had obtained further information with various methods including service reviews, needs assessment projects, case control studies, small area variations analyses, action research, and the use of focus groups. Interviewees had examined the validity of data in at least 61 $(41 \%)$ of the examples. They had made a wide range of changes to services including the development of local guidelines, the appointment of new personnel, the increased uptake of effective interventions, and improved targeting of preventive measures.

They had set up monitoring arrangements in most of the 147 examples, roughly half were 
Table 1 The 147 examples chosen

\begin{tabular}{lrl}
\hline Example & $n$ & Notes \\
\hline Coronary heart disease & 27 & $\begin{array}{l}\text { Includes use of coronary artery bypass grafts, } \\
\text { thrombolytic therapy, and cardiology services }\end{array}$ \\
Termination of pregnancy & 19 & \\
Mental health & 13 & Includes eight on suicide, two on schizophrenia, and one \\
& 11 & \\
Stroke & 10 & \\
Diabetes & 8 & \\
Breast cancer & 6 & \\
Renal replacement therapy & 5 & \\
Hip fracture & 4 & Includes two on hip replacement, one on knee \\
Joint replacement & & replacement, and one on both knee and hip replacement \\
& 4 & \\
Orchidopexy & 4 & \\
Cervical cytology & 3 & \\
Peptic ulceration & 3 & \\
Immunisation & 3 & \\
Asthma & 3 & \\
Subfertility & 2 & \\
Leg ulcers & 2 & \\
Dental health & 2 & \\
Glue ear and grommet & & \\
insertion & 2 & \\
Perinatal and infant mortality & 2 & \\
Use of steroids in preterm & 2 & \\
$\quad$ labour &
\end{tabular}

The following were chosen on one occasion: maternity care, low birthweight babies, vascular surgery, varicose veins, tuberculosis, tobacco smoking in young people, lung cancer, colorectal cancer, back pain, AIDS care, cataract surgery, orthopaedic services, and accidents.

Table 2 Most common reasons why clinical areas had been chosen

\begin{tabular}{ll}
\hline Reasons for the choice & $\begin{array}{l}\text { Clinical } \\
\text { areas }(n)\end{array}$ \\
\hline $\begin{array}{l}\text { Indicators using national data suggested that their district had an } \\
\text { outlying value }\end{array}$ & 50 \\
$\begin{array}{l}\text { Clinical area was a Health of the Nation area (but district did not have an } \\
\text { outlying indicator value) }\end{array}$ & 27 \\
$\begin{array}{l}\text { Analysis suggested variation within the district in a health outcome } \\
\text { based on a population }\end{array}$ & 20 \\
$\begin{array}{l}\text { Reacting to local concerns (including clinician concerns) } \\
\text { The health authority had decided that the area was an important local } \\
\text { issue or condition }\end{array}$ & 18 \\
Variations within the district in access for particular groups of people & 9 \\
The high costs of a particular service & 8 \\
\hline
\end{tabular}

*An outlying value meant that the value of an indicator for that district was high compared with the national mean. We did not measure these indicator values. Some respondents gave more than one reason and this table lists those which were the most common.

compared with national indicators to monitor changes and the rest with locally collected data.

None of the 147 examples saved costs of service delivery. There were at least 28 districts in which assessments of population health outcome had clearly identified unmet need, 10 of which had outlying indicator values. All of these assessments would have resulted in considerable increased investment.

CONSTRAINTS IN THE USE OF POPULATION BASED INDICATORS OF HEALTH OUTCOME

Table 3 contains the constraints identified. The health authorities had examined the validity of data in at least 61 of the 147 examples (41\%). This was more likely to happen if they used national comparative data and in certain clinical areas. For instance, all eight health authorities investigating suicide validated national data with local studies or confidential enquiries with coroner reports or death notifications. Routine data can both underestimate and overestimate a clinical problem and there were examples of both.
Health authorities used national comparative health outcome indicators based on populations to stimulate assessment of local health outcomes largely in Health of the Nation areas with outlying values.

The main perceived constraints in the use of health outcome indicators based on populations were: data validity and timeliness and the relevance of health outcomes to the quality of health care. The difficulties of changing clinical behaviour, and organisational change within health authorities also limited their usefulness.

The NHS could make population based health outcome indicators more useful if they were used in conjunction with evidence based process indicators.

Nearly a third of health authorities in this survey had developed their own indicators, mostly process indicators, and 10 were using their own indicators to manage the performance of local provider units.

Some of the indicators developed by health authorities may not be comparable between districts, as definitions of numerator and denominator data sometimes differ. We should encourage the standardisation of definitions used in such indicators.

Box 3 The key points from this study.

HOW POPULATION INDICATORS OF HEALTH OUTCOME COULD BE MADE MORE USEFUL Twenty three interviewees $(25 \%)$ spontaneously advocated the increased use of process indicators as proxies for health outcome. They used evidence based drug treatments as process indicators to monitor the delivery of health care. Twenty one interviewees mentioned the rates of use of thrombolytic agents after myocardial infarction, five the administration of steroids for preterm deliveries, and seven the use of PACT data-for example, the ratio of inhaled steroids to inhaled bronchodilators in the treatment of asthma.

Sixteen interviewees (18\%) expressed the need for or mentioned the usefulness of trends in indicators. Ten interviewees $(11 \%)$ found it more useful to compare their district's indicator values with other districts with a similar population structure, or with neighbouring districts, than to compare their indicator values nationally. Other areas in which interviewees said they wanted to use population indicators of health outcome were mental health, cancer services, coronary heart disease, primary care, stroke, diabetes, child health, and renal disease. Lack of routine data, resources, and time within their departments were the main reasons preventing them.

\section{HEALTH AUTHORITIES DEVELOPING THEIR OWN} INDICATORS

Twenty seven authorities (30\%) had developed their own provider based indicators of health outcome and of these 10 were using them to manage the performance of local providers. Clinical audit was an important means of 
Table 3 Constraints most commonly mentioned in the use of health outcome indicators by 91 interviewees

\begin{tabular}{|c|c|c|}
\hline Constraint & $n(\%)$ & Notes \\
\hline Data validity & $34(37 \%)$ & \\
\hline Clinical behaviour & $24(28 \%)$ & $\begin{array}{l}\text { There were problems in undertaking assessments and in } \\
\text { implementing change. Difficulties in gaining cooperation } \\
\text { from clinicians was mentioned on } 19 \text { occasions }\end{array}$ \\
\hline Organisational change & $17(19 \%)$ & $\begin{array}{l}\text { Nine commented that they had been unable to use such } \\
\text { assessments because of organisational change and of these } \\
\text { seven cited the staffing levels in their small public health } \\
\text { departments as the main constraint. Only half of those } \\
\text { interviewed had been in post for more than two years and } \\
\text { one fifth for more than three years }\end{array}$ \\
\hline Timeliness of data & $13(14 \%)$ & $\begin{array}{l}\text { Some mortality data were }>\text { two years out of date when } \\
\text { published }\end{array}$ \\
\hline $\begin{array}{l}\text { Lack of attributability on relevance of health } \\
\text { outcome indicators based on populations to } \\
\text { health care }\end{array}$ & $13(14 \%)$ & \\
\hline
\end{tabular}

Some interviewees identified more than one constraint.

developing these local indicators. Examples included complication rates and functional quality of life measures for hip replacement; outcome indicators in contracts for subfertility treatment; and outcome indicators for cataract surgery. Health authorities and hospitals could produce numerator and denominator data for many of these indicators more quickly than any comparative national package of indicators. Another 12 districts were at varying stages of developing their own indicators for possible use in managing local providers. Five districts described the development of their own indicators that were not focused on providers. These included supplementary Health of the Nation indicators, general practitioner prescribing indicators, healthy alliance indicators, and locality profiles containing indicators.

\section{Discussion}

ROLE OF POPULATION BASED INDICATORS OF HEALTH OUTCOME IN LOCAL HEALTH OUTCOME ASSESSMENTS

The study showed that indicators of health outcome based on the population within a health authority had a significant role in prompting districts to undertake assessments of health outcome within their population. Health authorities also used these indicators to examine local variations in health outcome and the indicators helped to highlight areas for further investigation, initiated data validation, and enabled the monitoring of changes to services. To some extent we validated the responses. We asked for health authority documents to support their examples and subsequently commissioned over 30 case studies from 18 health authorities. Over a third of these case studies focus on the use of national indicators. ${ }^{23 a}$

Table 4 Responses to question: is the management of performance of your health commission being judged on any local population health outcome indicators?

\begin{tabular}{lllll}
\hline Region in which health authority is placed & Yes & Future plans & No & Total \\
\hline Anglia and Oxford & 6 & 0 & 2 & 8 \\
North Thames & 3 & 0 & 9 & 12 \\
North West & 11 & 1 & 3 & 15 \\
Northern and Yorkshire & 5 & 1 & 4 & 10 \\
South and West & 4 & 3 & 5 & 12 \\
South Thames & 4 & 1 & 7 & 12 \\
Trent & 6 & 0 & 4 & 10 \\
West Midlands & 11 & 0 & 1 & 12 \\
Total & 50 & 6 & 35 & 91 \\
\hline
\end{tabular}

We were unable to interview representatives from four health authorities in the Northern and Yorkshire region, two in the West Midlands region, one in the Oxford and Anglia region, one in the North West region, and one in the North Thames region.
Our study had a high response rate $(91 \%)$ and consistency in interviewing. We asked for two local examples of clinical areas in which assessments of population based health outcomes had been of most value. We did not ask respondents to identify the use of all population based indicators of health outcome within their authorities.

CONSTRAINTS IN THE USE OF POPULATION BASED INDICATORS OF HEALTH OUTCOME

The validity and timeliness of data may improve if more health authorities and trusts use national indicators and re-examine their local data. The usefulness of such indicators is limited by the difficulty of changing clinical and organisational behaviour as are other aspects of health authority work especially at a time of organisational turbulence. In the United Kingdom part of the national research and development programme is to consider how best to implement research findings in practice. Research is also needed into the attributability of indicators to the quality of health care.

Despite such constraints in the use of population based indicators of health outcome they do have advantages over provider based indicators. The larger numbers mean that variation is less likely to be due to chance. Population based health outcomes also give a global assessment of outcome that incorporates those people not treated by providers. Variation between districts may still be due to differences in incidence of disease or to variation in data collection but such problems are more likely at a provider level. Many of the constraints such as data validity and relevance also apply to provider based health outcomes. ${ }^{24}$ It was perhaps surprising that we identified these constraints in so few interviewees. Further training may be required for those who use and interpret such indicators. ${ }^{25}$

HOW POPULATION INDICATORS OF HEALTH OUTCOME COULD BE MADE MORE USEFUL Interviewees suggested that population indicators of health outcome could be made more useful if they were used in conjunction with evidence based process indicators. Such process indicators are more readily available than indicators of health outcome, can be used at a 
subdistrict level or in contracting and audit, and can overcome or sidestep many of the problems that beset health outcome data such as attributability and interpretation. ${ }^{26}{ }^{27}$ They may be more meaningful to clinicians at a provider level than district based indicators of health outcome. They therefore may help to ensure that clinicians use the interventions in the correct way and on the appropriate people. The public health common data set user consultation document ${ }^{28}$ contained proposals for bringing process and outcome indicators together within a structural framework and a template for standardised specification of all indicators produced by the Department of Health's Central Health Outcomes Unit. Many of the indicators advocated as indicators of health outcome-such as those in box 2-are process indicators that are proxies for improved health outcome.

The public health common data set now presents trend data for many indicators. However, these may not be reliable as they have been analysed for the most recent health area boundaries and there have been changes in data coding systems at the former Office of Population and Surveys. ${ }^{23}$ Comparisons between districts with similar socioeconomic composition or with neighbouring districts are more likely to be useful than an overall league table, which could encourage complacency in districts that, although they are not outliers, are performing poorly relative to their socioeconomic profile. (The public health common data set now uses the classification system of the Office for National Statistics, which presents similar districts and grouped values. ${ }^{16}$ )

The programme in England to identify and develop sets of outcome indicators, already mentioned, ${ }^{18}$ will cover most of the areas highlighted by interviewees as topics in which they wanted to use indicators. At present the valid and timely indicators that can be used are limited by reliance on routine mortality and hospital data. The programme will make suggestions for new methods of data collection.

\section{HEALTH AUTHORITIES DEVELOPING THEIR OWN}

INDICATORS

In our survey at least a third of districts were developing their own indicators which can be relatively quick and easy to develop. Health authorities can produce their own indicators with data from local contracting and clinical audit, and now have considerable influence in funding and determining audit projects for providers. We would need further study to determine the extent to which these indicators were linked to a system of penalties or incentives and what was meant by the management of performance of local providers.

Some of the indicators developed by health authorities may not be comparable between districts, as definitions of numerator and denominator data sometimes differ. For example, we detected differences between districts in how they defined data for "door to needle time" for thrombolytic therapy after myocar- dial infarction, and mortality after hip fracture. The Department of Health and NHS Executive have a role in encouraging the standardisation of the definitions used in such indicators.

\section{Conclusions}

In this study we found that in health authorities population based indicators of health outcome had a significant role in prompting districts to undertake assessments of health outcome within their population. There were constraints on the use of such indicators and recommendations were made as to how they could be made more useful. A third of health authorities had developed their own indicators. The findings have and will influence the development of national comparative population based indicators of health outcome. Such indicators may have an increasing part to play in assessing the performance of English health authorities and NHS trusts (table 4).

We thank the 91 interviewees and Azim Lakhani, Anne Kauder, Veena Soni Raleigh, Michael Goldacre, Andrew Stevens, and Leigh Appleby for their advice and support. This work was funded by the Department of Health.

1 Blumenthal D. Quality of care: what is it? $N$ Eng $\mathcal{F}$ Med 1996;335:891-4.

2 Department of Health. Population health outcome indicators for the NHS. A consultation document. University of Surrey: Institute of Public Health, 1993.

3 Rockall TA, Logan RF, Devlin HB, et al. Variation in Rockall TA, Logan RF, Devlin $\mathrm{HB}$, et al. Variation in The national audit of acute upper gastrointestinal haemorrhage. Lancet 1995;346:346-50.

4 Todd CJ, Freeman CJ, Camilleri Ferrante C, et al. Differences in mortality after fracture of hip: the East Anglian audit. $B M \mathcal{F}$ 1995;310:904-8.

5 Payne N, Saul C. Variations in use of cardiology services in a health authority: comparison of coronary artery revascuarisation rates with prevalence of angina and coronary mortality. BMF 1997;314:257-61.

6 Bull AR, Hatton P, Bensley DC, et al. Standardized mortality from cervical cancer: a measure of performance? 7 Public Health Med 1994;16:16-22.

7 Payne JN, Milner PC, Saul C, et al. Local confidential inquiry into avoidable factors in deaths from stroke and hypertensive disease. BMF 1993;307:1027-30.

8 Wolfe CD, Taub NA, Woodrow J, et al. Does the incidence, severity, or case fatality of stroke vary in southern England? f Epidemiol Community Health 1993;47:139-43.

9 Secretary of State for Health. The health of the nation: a strategy for health in England. London: HMSO, 1992.
end

10 Department of the Environment, Department of Health. Public health: responsibilities of the NHS and the roles of others. Department of the Environment, Department of Health, 1993

11 Stirling A. The Dobson agenda. Pulse 1997;57:12

12 Department of Health, NHS Executive. Public health in England: roles and responsibilities of the Department of Health and the NHS. London: Department of Health, NHS Executive, 1994

13 McColl AJ, Gulliford MC. Population health outcome indicators for the NHS. a feasibility study. London: Faculty of Public Health Medicine and the Department of Public Health Medicine, United Medical and Dental Schools of Guy's Medicine, United Medical and
and St Thomas' Hospitals, 1993.

14 Rutstein DD, Berenberg W, Chalmers TC. Measuring the quality of medical care: a clinical method. $N$ Engl $f \mathrm{Med}$ quality of medical

15 Charlton JRH, Hartley RM, Silver R, et al. Geographical variation in mortality from conditions amenable to medical intervention in England and Wales. Lancet 1983;691-6.

16 Department of Health. Public Health Common Data Set 1995. Incorporating population health outcome indicators for the NHS. Data definitions and user guide for computer files. London: University of Surrey: Institute of Public Health, 1995.

17 Scottish Office. Clinical outcome measures: report: Fune 1993. Edinburgh: Scottish Office, 1993.

18 Goldacre MJ, Ferguson J. Introduction to the work and report of the outcome indicators development workshop held at the Royal Society of Medicine, 12th fanuary 1995. Oxford: Unit of Health Care Epidemiology, Department of Pub
Health and Primary care, University of Oxford, 1995.

19 Department of Health. The National Health Service: a service with ambitions. London: HMSO, 1996. 
20 Walshe K, Ham C. Who's acting on the evidence? Health Service fournal 1997;107:22-5.

21 Warden J. The new health team's portfolios. BMf 1997;314 1434 .

22 Frater A, Dixon P. A survey of purchaser's use of health outcome assessment. Leeds: UK Clearing House on Health Outcomes, The Nuffield Institute for Health, 1993.

23 McColl AJ, Ferris G, Roderick P, et al. How do English DHAs use population health outcome assessments? Southampton: Univeristy of Southampton, Wessex Institute of Public Health Medicine, 1996.

23a McColl AJ, Roderick P, Gabbay J. Improving health outcomes: based health outcome assessments. Southampton: University of
Southampton, Wessex Institute for Health Research and Development, 1997. (http://www.soton.ac.uk/ wi/)

24 McKee M, Hunter D. Mortality league tables: do they inform or mislead? Quality in Health Care 1995;4:5-12.

25 Kazandjian VA. Indicators of performance or the search for the best pointer dog. In: Kazandjian VA, ed. The epidemiology of quality. Maryland: Aspen, 1995.

26 Mant J, Hicks N. Detecting differences in quality of care: the sensitivity of measures of process and outcome in treating acute myocardial infarction. BMF 1995;311:793-6.

27 Davies HT, Crombie IK. Assessing the quality of care. BMF 1996;311:766.

28 NHS Executive. Public health common data set: a user consultation. 1995. 